\title{
Evaluation the efficacy of three brands of ceftriaxone against various strains of bacteria by measuring zone of inhibition
}

\begin{abstract}
Ceftriaxone (Rocephin) is wide spectrum cephalosporin that has been used for decades for combating infections caused by broad array of pathogens. In this study, the antibiotic ceftriaxone from three different brands was tested for its effectiveness against strains of bacteria like Streptococcus pyrogenes, Staphylococcus aureus and Klebsiella pneumonia. The effectiveness of ceftriaxone was estimated by measuring zone of inhibition and compared with standard disc (BD BBL Sensi-Disc 2004/09). The diameters of the inhibitory zones for all brands were ranged from 20 to $33 \mathrm{~mm} \pm 0.5$. The present study showed that there is no significant variation amongst the different brands of ceftriaxone in term of their antibacterial effectiveness.
\end{abstract}

Keywords: ceftriaxone, zone of inhibition, antibacterial efficacy
Volume 8 Issue 6 - 2020

\author{
Ibrahim Egfair,' Ryad MO Alati,' Abdullah \\ MO Bakoosh, ${ }^{2}$ Abu Ajeela M Alfalos, ${ }^{2}$ \\ Mahmoud AL Ruaua, ${ }^{3}$ Ashraf A Naass, ${ }^{3}$ \\ Waleed RA Abusittah, ${ }^{4}$ Mahmud EL \\ Abushhewa $^{4}$ \\ 'Faculty of Pharmacy, Alasmarya Islamic University, Libya \\ ${ }^{2}$ Faculty of Medicine, Alasmarya Islamic University, Libya \\ ${ }^{3}$ Biotechnology Research Centre, Libya \\ ${ }^{4}$ Faculty of Medicine, Azzaytuna University, Libya
}

Correspondence: Dr. Mahmud Abushhewa, Department Biochemistry and Molecular biology, Faculty of Medicine, Azzaytuna University, Libya, Tel + 21891 6224369 or 92 8872267, Email alhmroni82004@yahoo.com.au

Received: October 07, 2020 | Published: November 12, 2020

\section{Introduction}

Ceftriaxone (Beta-lactam antibiotics) is a broad spectrum third generation of cephalosporin. ${ }^{1}$ It is highly effective against Gram negative as well as Gram positive organisms. Ceftriaxone is unique because of its prolonged serum half-life, which permits once- or twice-daily dosing of this member of Cephalosporin family. ${ }^{2}$ The drug has better penetration into the cerebrospinal fluid and is useful in the treatment of bacterial meningitis. The dose of ceftriaxone is 50 $\mathrm{mg} / \mathrm{kg}$ per day in neonates and $100 \mathrm{mg} / \mathrm{kg}$ per day in older infants. It displaces bilirubin from albumin binding sites and increases the unconjugated free bilirubin in plasma. It should only be given with great caution in infants with high unconjugated plasma bilirubin level. ${ }^{3}$ Ceftriaxone has a longer half-life than other cephalosporin; the plasma half-life of ceftriaxone is 15 hours at birth and 7 hours over 2-4 weeks. ${ }^{4}$ It has high potency against all the Enterobacteriaceae, Haemophilus influenzae, the Nisseria and most Gram-positive cocci except Enterococcal spp. ${ }^{5}$ This study aimed to evaluate the efficacy of different brands of ceftriaxone locally available against strains of bacteria like staphylococcus aureus, streptococcus pyogens and Klebsiella.

\section{Material and methods}

\section{Study design}

In this experiment, the effectiveness of three different brands of Ceftriaxone on three strains of bacteria was determined by measuring and comparing their zones of inhibitions with control. ${ }^{5}$ The bacterial samples (Streptococcus pyrogens type B, Staphylococcus aureus and Klebsiella pneumonia) were isolated from sample analysis laboratory in Zliten Teaching Hospital between May to August 2018 following the standard procedure. ${ }^{5,6}$ The bacterial strains were identified and their testing of susceptibility was done with BD Phoenix ${ }^{\mathrm{TM}}$ and API method.

Furthermore, three different brands of Ceftriaxone injection dosage form having strength of $1 \mathrm{~g} / \mathrm{ml}$ were used. The three brands were Ceftriaxone (B), (A) and Ceftriaxone (C). The stock solution of antibiotics was prepared in the following manner. One ampule was diluted to $1000 \mathrm{ml}$. The formula

$$
\mathrm{W}=\frac{1000}{\mathrm{P}} \times \mathrm{V} \times \mathrm{C}
$$

Where $\mathrm{P}$ is potency of antibiotics, $\mathrm{V}$ is volume $(\mathrm{ml})$ required; $\mathrm{C}$ is final concentration of solution $(\mathrm{mg} / \mathrm{ml})$ and $\mathrm{W}$ is weight of the antimicrobial taken (mg). The Mueller-Hinton agar was used for culturing S. Pyogenes type B, Staphylococcus and Klebsiella pneumonia. .,7 $^{6}$

\section{Microbiological methods}

The Mueller-Hinton agar media, 8 in number were prepared for inoculation and culture of S. Pyrogens type B, Staphylococcus aureus and Klebsiella pneumonia. The agar plates were labelled and marked for standard, test samples and control. ${ }^{5,7}$ Under aseptic conditions, inoculate one plate with Klebsiella pneumonia broth culture using a sterile swab. Thoroughly swab the surface of the plate to cover the entire surface turn the plate to approximately ${ }^{\circ} 60$ and repeat the previous step. ${ }^{5,7}$ The standard disc was put into the surface of agar using sterile technique. Two holes were bored with help of sterile borer having diameter of $10 \mathrm{~mm}$ and test samples of the antibiotic were poured in each hole. This procedure was similar for the plates containing $S$. Pyrogens type B, Staphylococcus and Klebsiella pneumonia culture. All the plates were left for 5 minutes in order to dry completely. The plates were incubated at $37^{\circ} \mathrm{C}$ in German incubator for 48 hours. The 
diameters for the zone of inhibitions were measured by grade ruler and results were compared with that of the standard disc. ${ }^{6-8}$

\section{Statistical analysis}

The categorical variables between the plates were analysed using the excel program of Microsoft 2016 to measure average values of inhibitory zones of all samples, means and standard deviations were compared with the standard.

\section{Result and discussion}

The results of treated samples were as following; the highest inhibitory zone was found in bacterial culture treated with brand $\mathrm{B}$ ceftriaxone (25.66 \pm 1.15$)$, however, the sizes of inhibitory zone in brand $A$ and brand $C$ ceftriaxone were found $25 \pm 2 \mathrm{~mm}$ and $20 \pm 1 \mathrm{~mm}$ respectively (Table 1, Figure 1). On the other hand, the size of inhibitory zone in control samples was $25.66 \pm 1.15 \mathrm{~mm}$ which indicated that it is more effective against Staphylococcus aureus.

Table I Zone of inhibition of three brands of ceftriaxone against Staphylococcus aureus

\begin{tabular}{|c|c|c|c|c|}
\hline \multirow{2}{*}{$\begin{array}{l}\text { Dose of } \\
\text { Ceftriaxone } 30 \mu \mathrm{g}\end{array}$} & \multicolumn{4}{|c|}{ Staphylococcus aerus } \\
\hline & Exp-0I & Exp-02 & Exp-03 & Mean $\pm S D$ \\
\hline Control & 22 & 22 & 20 & $21.33 \pm 1.15$ \\
\hline Control & 27 & 25 & 23 & $25 \pm 2$ \\
\hline (A) & 25 & 27 & 25 & $25.66 \pm 1.15$ \\
\hline (B) & 21 & 19 & 20 & $20 \pm 1$ \\
\hline
\end{tabular}

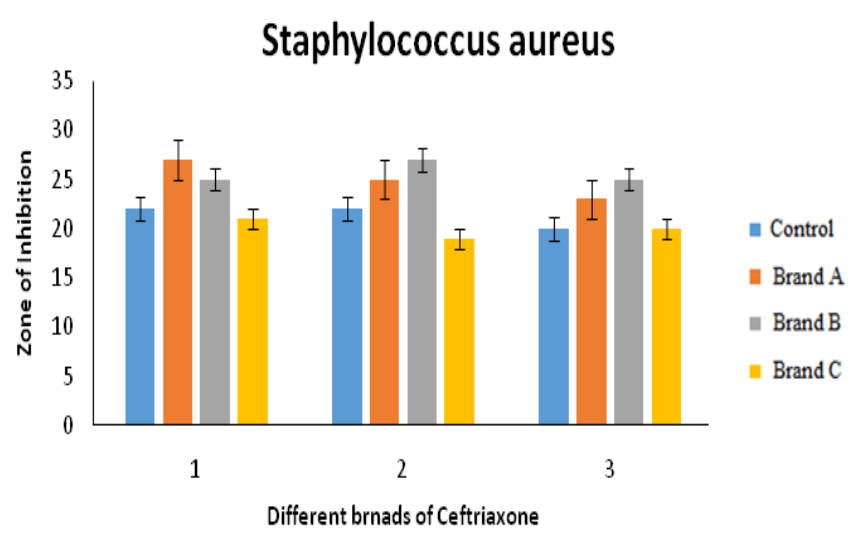

Figure I Effect of three ceftriaxone brands against Staphylococcus aureus.

In case of Streptococcus strain, the mean inhibitory zone was $24.33 \pm 1.15 \mathrm{~mm}$ as according to the control. The diameters of the inhibitory zones of ceftriaxone for Ceftriaxone (B) and Ceftriaxone (C) were similar, $27.66 \pm 0.57 \mathrm{~mm}$, whereas (A) gave $26.66 \pm 0.57 \mathrm{~mm}$. All these results showed inhibitory diameters were adequately within the required range for Streptococcus pyrogens types $B$ (table 2, figure 2).

For the bacteria Klebsillea Pneumonia, the mean diameter of inhibitory zone for control was $25 \pm 3.0 \mathrm{~mm}$. Furthermore, the diameter of inhibitory zone for (A) was $33 \mathrm{~mm}$. The mean diameter of inhibitory zone for Ceftriaxone (B) was $29 \pm 6.55 \mathrm{~mm}$. The mean diameter for the zone of inhibition Ceftriaxone (C) was $31.6 \pm 1.52 \mathrm{~mm}$ (Table 3, figure $3)$.
Table 2 Zone of inhibition of three brands of ceftriaxone against Streptococcus pyogenes

\begin{tabular}{|c|c|c|c|c|}
\hline \multirow{2}{*}{$\begin{array}{l}\text { Dose of } \\
\text { Ceftriaxone } 30 \mu \mathrm{g}\end{array}$} & \multicolumn{4}{|c|}{ Streptococcus pyogens } \\
\hline & Exp-0I & Exp-02 & Exp-03 & Mean $\pm S D$ \\
\hline Control & 25 & 23 & 25 & $24.33 \pm 1.15$ \\
\hline (A) & 27 & 26 & 27 & $26.66 \pm 0.57$ \\
\hline (B) & 27 & 28 & 28 & $27.66 \pm 0.57$ \\
\hline (C) & 27 & 28 & 28 & $27.66 \pm 0.57$ \\
\hline
\end{tabular}

Streptococcus pyogenes

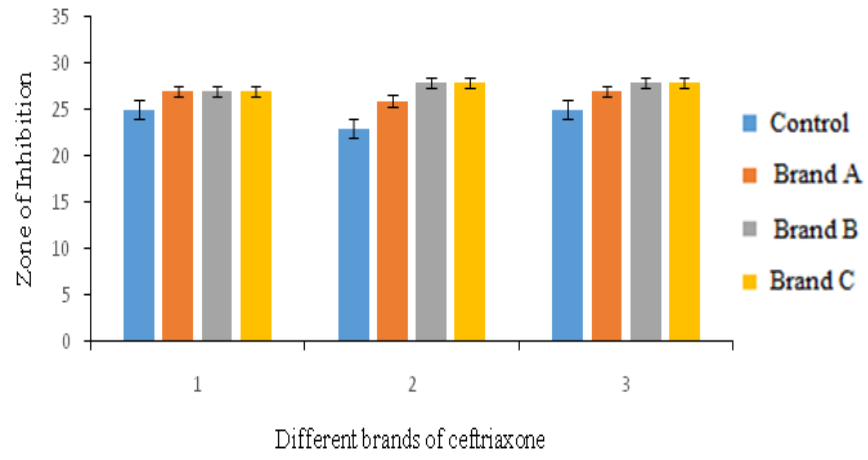

Figure 2 Effect of three ceftriaxone brands against Streptococcus pyogenes.

Table 3 Zone of inhibition of three brands of ceftriaxone against Klebsiella pneumoniae

\begin{tabular}{|c|c|c|c|c|}
\hline \multirow{2}{*}{$\begin{array}{l}\text { Dose of } \\
\text { Ceftriaxone } 30 \mu \mathrm{g}\end{array}$} & \multicolumn{4}{|c|}{ Klebsiella pneumoniae } \\
\hline & Exp-0I & Exp-02 & Exp-03 & Mean士S.D \\
\hline Control & 25 & 28 & 22 & $25 \pm 3$ \\
\hline (A) & 33 & 33 & 33 & 33 \\
\hline (B) & 30 & 22 & 35 & $29 \pm 6.55$ \\
\hline (C) & 30 & 32 & 33 & $31.66 \pm 1.52$ \\
\hline
\end{tabular}

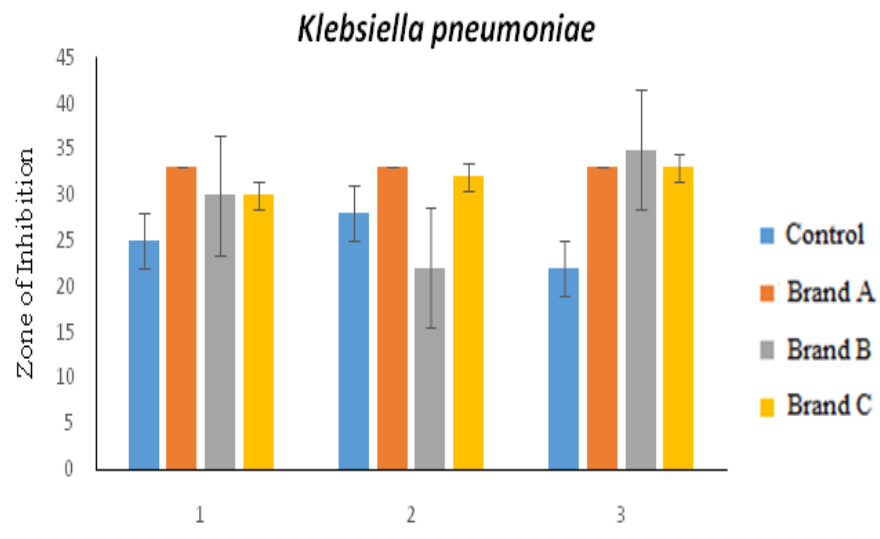

Different brand of Ceftriaxone

Figure 3 Effect of three ceftriaxone brands against Klebsiella pneumoniae.

According to (BNF 57, 2009), Ceftriaxone was showed the following results, S. aureus was $96.1 \%$ of the isolates inhibited by ceftriaxone. While, E. coli (95\%), P. aeruginosa $(92.7 \%), K$. 
pneumonia (89.4\%) and S. Typhi (87.2\%). ${ }^{9}$ The result showed that there is no significant variation between the brands in term of content and potency. The results with both the strains of bacteria were same in response to antibiotics treatment. Although the mean of diameters of each brand were different, but they were within the pharmacopeia limit. Minimum inhibitory concentration (MIC) for the three ceftriaxone brands was ranged from $<0.25$ to $>256 \mathrm{mg} / \mathrm{L}$. The MIC for both A and $\mathrm{C}$ ceftriaxone were reliable for all isolates. Sequentially, MIC for brand $\mathrm{B}$ was higher by at least double concentration, suggesting this brand had the lowest in-vitro activity against isolates tested. ${ }^{10}$ In this study, Staphylococcus aureus, which represents $19 \%$ of the total isolates tested, showed $23.4 \%(11 / 47)$ and $34 \%(16 / 47)$ resistance to ceftriaxone and ceftazidime, respectively. Correspondingly, Klebsiella pneumoniae showed $46.1 \%(12 / 26)$ resistance to ceftriaxone. ${ }^{11}$

\section{Conclusion}

This aspect of the research suggested that, the used brands had different diameters of inhibitory zones and this may be due to the storage condition or other physicochemical reasons. Alternatively, in this study, Ceftriaxone (B), (A) and (C), showed similar bactericidal effect on Staphylococcus pyogens (type B). Therefore, this type of study can be incorporated on other brands of different antibiotic classes as criteria to evaluate them and to improve their efficacy.

\section{Acknowledgments}

None.

\section{Conflicts of interest}

Authors declare that there is no conflict of interest.

\section{References}

1. Nath SK, Foster GA, Mandell LA, et al. Antimicrobial activity of ceftriaxone versus cefotaxime: negative effect of serum albumin binding of ceftriaxone. J Antimicrob Chemother. 1994;33(6):1239-1243.
2. Masood H, Naqvi SB, Aslam N. Cost effective analysis of different brands of ceftriaxone available in Karachi Pakistan. Pak J Pharmacol. 2008;25:13-19

3. Pacifici GM, Marchini G. Clinical Pharmacology of Ceftriaxone in Neonates and Infants: Effects and Pharmacokinetics Systematic Review. Int J Pediatr. 2017;5(9):5751-5777.

4. Hwang KP, Tang YF, Shen YH. Activity of ertapenem, ciprofloxacin, ceftriaxone, piperacillin-tazobactam, and ampicillin-sulbactam against 12 common clinical isolates of community-acquired bacteremia. J Microbiol Immunol Infect. 2009;42(5):433-438.

5. James C. Instructor's guide for microbiology: A laboratory manual. 10th ed. Paperback: Addison Wesley; 2011.

6. Clinical and laboratory standards institute. 2nd ed; 2004.

7. Hudzicki J. Kirby-Bauer Disk Diffusion Susceptibility Test Protocol. ASM Microbe Library: American Society for Microbiology; 2009.

8. BNF 57. Wholly-owned published, BMJ group and RPS publishing; 2009. ISBN: 9780853698456

9. Syed HM, Aslam N. In Vitro Susceptibility Test of Different Clinical Isolates against Ceftriaxone. Oman Medical Journal. 2010;25(3):199202.

10. Thapa B, Mahat K. In-vitro Activity of Three Brands of Ceftriaxone against different clinical isolates. JNMA J Nepal Med Assoc. 2010;49(179):225227.

11. Fanta G, Eshetu M, Mekidim M, et al. Antimicrobial Resistance Profile of Different Clinical Isolates against Third-Generation Cephalosporins. Journal of Pharmaceutics. 2018;2018:5070742. 